\title{
USAHA TERNAK AYAM SENTUL MELALUI OPTIMALISASI PEMANFAATAN FEED ADDITIVE HERBAL DI KELOMPOK TANI RANCA BAWANG 1
}

\author{
Tuti Widjastuti, Iwan Setiawan, Wiwin Tanwiriah dan Dani Garnida \\ Fakultas Peternakan Universitas Padjadjaran \\ E-mail: Tuti_widjastuti@yahoo.com
}

\begin{abstract}
ABSTRAK. Kegiatan KKN-PPMD Integratif dari universitas Padjadjaran telah dilakukan kepada anggota kelompok Tani Ranca Bawang I yang tertarik beternak ayam lokal di Desa Cinanjung, kecamatan Tanjungsari Kabupaten Sumedang dari bulan Juli hingga bulan November tahun 2019. Tujuan dari kegiatan ini adalah untuk meningkatkan pengetahuan dan keterampilan kepada anggota kelompok Tani Ranca Bawang I mengenai budidaya beternak ayam lokal, menetaskan telur, menyusun ransum, dan pengolahan hasil ternak ayam berupa daging ayam olahan seperti baso dan nugget. Metode kegiatan adalah dengan cara penyuluhan, praktek pembuatan nugget dan baso dari daging ayam serta demonstrasi penyusunan ransum dan pembuatan kandang. Dari kegiatan ini antusiasme peserta untuk memperoleh pengetahuan dan keterampilan usaha budidaya beternak ayam lokal cukup tinggi. Wawasan peserta mengenai tatalaksana pemeliharaan ayam, pembuatan baso daging ayam dan nugget serta penyusunan ransum masih sangat kurang, tetapi animo peternak sangat baik untuk belajar semua pengetahuan tentang budidaya beternak ayam lokal, sehingga kegiatan ini dapat meningkatkan pengetahuan, keterampilan dan semangat untuk usaha beternak ayam lokal secara intensif memalui manajemen pakan dan pemanfaatan feed additive herbal.
\end{abstract}

Kata kunci: Ayam lokal; budidaya; feed additive herbal; baso, nugget

ABSTRACT. The Integrative KKN-PPMD activity from Universitas Padjadjaran was carried out to members of the Ranca Bawang I Farmer group who were interested in raising local chickens in Cinanjung Village, Tanjungsari Regency, Sumedang Regency from July to November 2019. The purpose of this activity is to increase knowledge and skills for members of the Ranca Bawang I Farmer group on management local chicken, hatching eggs, preparing rations, and processing chicken products in the form of processed chicken meat such as meatballs and nuggets. The method of its activities is through counseling, the practice of making nuggets, meatballs from chicken meat and demonstration of ration preparation and making of chicken housing. From this activity the enthusiasm of the participants to gain knowledge and business skills of raising local chickens was quite high. Participants' insights on the management of chicken rearing, making chicken meatballs and nuggets as well as the preparation of rations were still lacking, but the animo of breeders was very good for learning all the knowledge about local chicken breeding, so that this activity could increase knowledge, skills and enthusiasm for local chicken raising businesses intensively through feed management and utilization of herbal feed additives.

Keywords: Local chicken; management; feed additive herbs; meatballs; nuggets

\section{PENDAHULUAN}

Desa Cinanjung merupakan salah satu Desa di Kecamatan Tanjungsari, Kabupaten Sumedang. Luas Desa Cinanjung adalah $373 \mathrm{Ha}$, Sebelah utara berbatasan dengan Desa Jatisari, Desa Margajaya, Desa Tanjungsari, Sebelah selatan dengan Desa Jatiroke, Desa Hegarmanah, Sebelah barat dengan Desa Kutamantri, dan Sebelah Timur dengan Desa Raharja. Desa Cinanjung hanya berjarak $3 \mathrm{~km}$ dari ibukota kecamatan. Kontur tanahnya berbukit-bukit, berada di lereng gunung sehingga Desa Cinanjung berada di kawasan dataran tinggi. Desa Cinanjung memiliki iklim tropis, curah hujan sebesar $50 \mathrm{~mm} /$ $\mathrm{m}^{2}$ selama 3 bulan panjangnya serta suhu lingkungan yang tidak terlalu panas yaitu $24^{\circ} \mathrm{C}$ dan ketinggian 879 mdpl.

Berdasarkan hasil diskusi bersama Kepala Desa, didapati bahwa sebagian besar penduduk Desa Cinanjung adalah petani dan peternak ayam, juga diketahui bahwa kegiatan-kegiatan ibu rumah tangga di Desa Cinanjung adalah terbilang sangat aktif yaitu terdapat Kelompok Wanita Tani di setiap Rukun Warga. Pertimbangan pemilihan kelompok Tani Ranca Bawang I adalah berdasarkan pada kondisi kelompok ini sudah berjalan pada usaha peternakan ayam broiler dan petelur yang menghasilkan produksi daging dan telur, namun para peternakan mengalami kesulitan yang kian menghambat khususnya yang bergerak di bidang intensifikasi ayam broiler mengalami kerugian. Pengaruh DOC, ransum dan obat-obatan yang sangat fluktuatif tanpa diikuti keseimbangan harga jual komoditas, akhirnya banyak peternak gulung tikar. Kelemahan yang terjadi berpangkal dari bibit tidak tersedia secara kontinyu, ransum dan obat-obatan yang harganya semakin melonjat. Oleh karena itu peternak yang tergabung dalam kelompok Tani Ranca Bawang ingin beralih usahanya dengan memelihara ayam lokal lain yaitu ayam Sentul. Mereka berpendapat kalau memelihara ayam local/sentul akan jauh lebih menguntungkan karena selain dapat menjual telur juga dapat menjual ayam sebagai penghasil daging. Pengembangan ayam kampung/lokal mempunyai prospek yang cukup 
baik karena (1) tingginya preferensi masyarakat terhadap produk ayam lokal karena rasa daging yang khas; (2) terdapat kecenderungan beralihnya pangsa konsumen tertentu dari produk daging berlemak ke produk daging yang lebih organik dan (3) adanya pangsa pasar ayam lokal tersendiri yang tercermin dari semakin banyak restoran yang menggunakan ayam lokal seperti Ayam Suharti, Ayam Kalasan dan lain-lain. Akan tetapi keunggulan tersebut perlu ditunjang dengan cara pemuliaan yang harus serius dilakukan, perlu perbaikan mutu pakan dan sistem pemeliharaan. Penggunaan obat-obatan dari herbal disarankan, karena ayam yang dihasilkan bebas residu kimia dan termasuk ayam lokal semi organic.

Landasan umum mengapa dipilih ayam Sentul yang ingin dibudidayakan secara intensif, karena ayam sentul adalah plasma nutfah Jawa barat, produktivitas telurnya cukup tinggi yaitu 12-30 butir telur dalam satu periode peneluran dan tubuhnya mempunyai perototan yang padat (kompak) dan daging yang cukup baik, serta mampu beradaptasi terhadap berbagai kondisi lingkungan dan terbiasa dengan pakan berkualitas rendah. Produksi telur ayam Sentul per tahun antara 118-140 butir dengan bobot telur rata-rata 40,7 gram (Kementan RI, 2013). Ayam Sentul oleh masyarakat Ciamis dikenal dengan sebutan ayam Kulawu (abu-abu). Ayam ini sering dihubungkan dengan si Jelug, ayam kesayangan Ciung Wanara yang merupakan tokoh legenda masyarakat Ciamis. Nama Sentul sendiri berasal dari nama buah Sentul yang berwarna abuabu kekuningan (Alam, 2005). (Gambar 1)

Ayam Sentul memiliki keunggulan kompetitif dan mudah beradaptasi dengan lingkungan. Tubuh ayam Sentul mempunyai perototan yang padat (kompak) dan daging yang cukup baik, serta mampu beradaptasi terhadap berbagai kondisi lingkungan dan terbiasa dengan pakan berkualitas rendah (Widjastuti dkk., 2016). Upaya kearah peningkatan performa ayam sentul tersebut perlu dilakukan atas pendekatan teknologi peternakan. Pengenalan ransum bermutu tinggi, manajemen berkesinabungan merupakan syarat mutlak serta upaya perbaikan mutu bibit ayam dalam pencapaian keseragaman. Pemanfaatan jenis bahan-bahan pakan nabati yang kurang diketahui atau dipahami peternak di lingkungan setempat serta bernilai input rendah perlu dikenalkan. Kondisi kandang dan peralatan yang memenuhi disain, diikuti dengan biosekurity diseluruh areal kandang harus diterapkan. Pola pemeliharaan yang terkontrol dan tercatat dengan sistematis perlu dikenalkan secara berkesinambungan serta mampu menjalankan mesin tetas agar dapat selalu tersedia DOC yang berkualitas (Tuti Widjastuti, dkk 2016). Bila keseluruhan kegiatan program teknologi peternakan dapat diaplikasikan oleh anggota, maka sudah tentu pada waktu mendatang pendapatan mereka lebih meningkat.Agar usaha ternak ayam lokal sentul pada kelompok Tani Ranca Bawang melalui perbaikan teknologi peternakan dapat tercapai sesuai dengan rencana, maka dalam pelaksanaan penyuluhan dan keterampilan perlu didukung oleh tenaga sivitas akademi dosen Fakultas Peternakan Universitas Padjadjaran.

\section{METODE}

Metode yang digunakan adalah penyuluhan budidaya ayam lokal/sentul secara umum, penyuluhan tentang mesin tetas, penanganan telur tetas, penyuluhaan perkandangan, penyuluhan dan praktek pemeliharaan anak ayam dan menyusun ransum serta praktek pembuatan baso dan nugget dari daging ayam. Tempat dan waktu kegiatan dilaksanakan kegiatan PKM di Desa Cinanjung Kecamatan Tanjungsari, Kabupaten Sumedang. Khalayak sasaran pada kegiatan PKM ini adalah peternak anggota kelompok Tani Ranca Bawang I dan masyarakat umum yang tertarik dalam budidaya ayam lokal, yang ada di desa Cinanjung Kecamatan Tanjungsari Kabupaten Sumedang.

Metode kegiatan yang dilakukan beberapa cara yaitu:

1. Menginventarisasi para warga dan anggota kelompok Tani Rancabawang yang akan menjadi sasaran, pelaksanaan dibantu mahasiswa yang sedang KKN di desa tersebut

2. Penyuluhan cara beternak ayam kampung
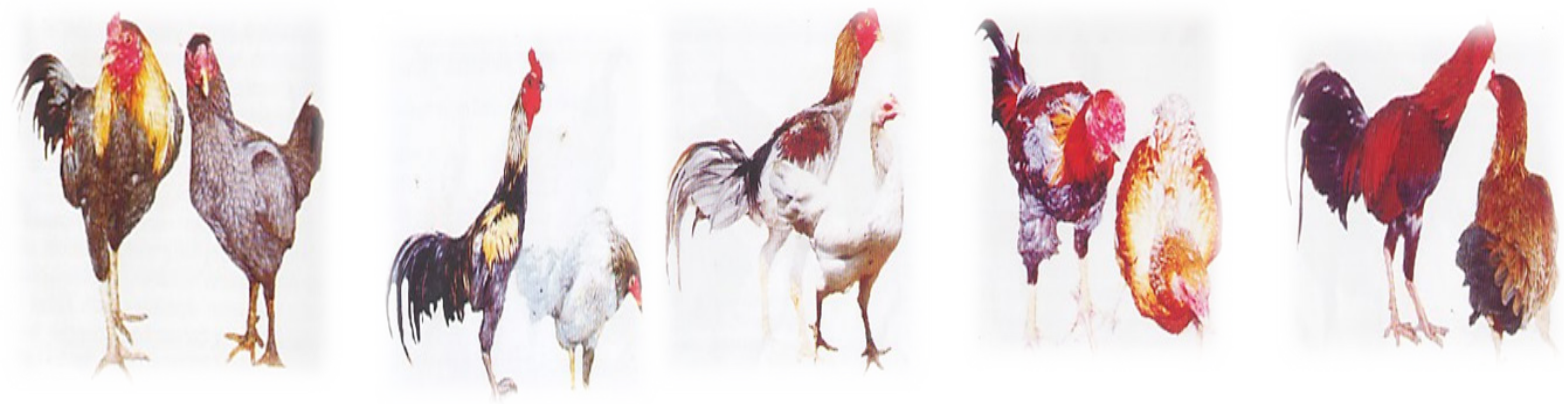

(Dinas Kab. Ciamis, 1996)

\section{Gb 1. Gambar Berbagai Tipe Ayam Sentul}


3. Penyuluhan pakan dan Praktek

4. Penyuluhan Penetasan dan demostrasi pembuatan mesin tetas 5 .

5. Praktek pembuatan nugget dan baso dari daging ayam

6. Chick anak ayam kampung untuk dipelihara oleh anggota kelompok Tani Ranca Bawang

\section{HASIL DAN PEMBAHASAN}

Penyuluhaan dan praktek mengenai Aplikasi Usaha Ternak Ayam Sentul melalui Optimalisasi Pemanfaatan Limbah Pertanian dan Feed Additive di Kelompok Tani Rancabawang dilaksanakan mulai bulan Juli sampai dengan November 2019. Kegiatan penyuluhan yang pertama dilakukan pada Kelompok Tani Desa Cinanjung dilaksanakan pada hari Sabtu, tanggal 13 Juli 2019, yang berlokasi di Biomethagreen, RW 04 Desa Cinanjung. Kegiatan ini dihadiri di antaranya oleh Penyuluh Pertanian Lapangan, Kelompok Wanita Tani, dan kelompok peternak Desa Cinanjung yang berjumlah lebih kurang 40 orang. Materi yang disampaikan pada topik ini di antaranya adalah pengenalan terhadap berbagai jenis ayam kampung/lokal dan ayam sentul serta karakteristik dan kelebihan masing-masing jenis ayam. Di mana jenis ayam lokal disarankan untuk dijadikan hewan ternak budidaya dibandingkan dengan ayam broiler dan ayam ras petelur, jika dilihat dari kandungan gizi dalam daging dan telur yang dihasilkan cukup tinggi dan mempunyai cita rasa yang disukai masyarakat.

Penyuluhan yang kedua pelaksanaan dilakukan tanggal 19 Juli 2019 di aula Biomethagreen, RW 04 DesaCinanjung. Topikpenyuluhanadalahmanagemen pemeliharaan, perkandangan dan managemen penetasan. Materi yang disampaikan pada topik ini adalah mengenai bagaimana para peternak perlu memperhatikan dan mempertimbangkan pemilihan bangunan perkandangan yang digunakan serta proses managemen pemeliharaan yang dianjurkan. Jenis kandang yang disarankan kepada peternak di Desa Cinanjung jika akan berternak ayam kampung baik petelur atau pun pedaging adalah kandang semiintensif yaitu dengan menggunakan kandang sistem terbuka (open House) dengan pemberian pakan secara teratur. Selain itu dipaparkan pula bagaimana proses biosekurity yang baik, yaitu di anjurkan menggunakan detergen, kapur, dan desinfektan

Penyuluhan managemen penetasan yang disampaikan yaitu mengenai bagaimana para peternak dapat menyeleksi telur tetas yang baik untuk ditetaskan, peralatan apa yang digunakan dan teknik untuk melaksanakan penetasan serta bagaimana cara membuat mesin tetas yang sederhana.
Penyampaian teori mengenai budidaya ayam kampung/sentul diberikan seminimal mungkin untuk menjaga konsentrasi peserta, sebagai gantinya adalah praktek mengenai budidaya beternak ayam kampung/sentul. Dari hasil diskusi diketahui ada beberapa anggota kelompok Tani Rancabawang I bertanya untuk berhasil usahanya terutama mengenai pemanfaatan bahan pakan dan limbah untuk dicampurkan dalam ransum ayam lokal. Juga bertanya mengenai pemanfaatan tanaman herbal untuk pencegahan dan pengobatan ternak khususnya ayam kampung. Dalam dikusi tersebut diketahui pula bahwa anggota peternak masih memiliki wawasan yang kurang dalam bidang pakan, kebersihan kandang dan penyakit yang sering menyerang secara umum dan cara pengobatan dengan menggunakan obat-obatan herbal.

Kegiatan yang ketiga dilakukan pada, tanggal 25 Juli 2019 yang berlokasi di Biomethagreen Desa Cinanjung, dengan ibu-ibu anggota kontak tani Rancabawang I yaitu kegiatan penyuluhan dan praktek "Cara Pembuatan Nugget dan Bakso" yaitu kegiatan yang dilaksanakan dengan tujuan memperkaya pengetahuan dan pengalaman peserta dalam mengolah hasil produk ternak berupa daging . Kegiatan penyuluhan diawali dengan pemaparan oleh Tim PKM mengenai teknik pembuatan, bahanbahan yang diperlukan untuk membuat kedua produk olahan, yang kemudian dilanjutkan dengan praktek langsung pembuatan nugget dan bakso. Setelah kedua produk olahan selesai dibuat dan disajikan, kemudian dilanjutkan dengan acara makan siang bersama juga foto bersama sebagai penutup rangkaian acara.

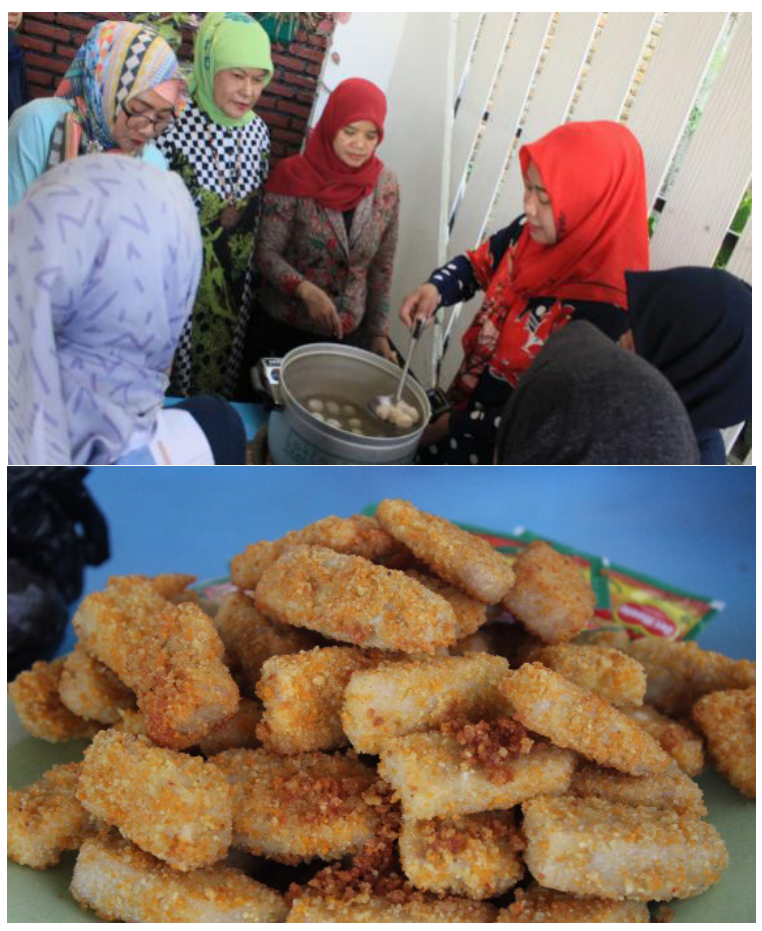

Gambar 2. Praktek Pembuatan Baso dan Nugget 
Kegiatan lain adalah Pelaksanaan Kegiatan Chick In anak ayam kampung dan pemeliharaan pada Kelompok Tani Rancabawang di Desa Cinanjung. Pelaksanaan Chick in DOC ayam kampung sebanyak 200 ekor dan bantuan pakan untuk awal pemeliharaan sebanyak $50 \mathrm{~kg}$ yang dibagi pada 4 anggota kelompok Tani dan penjelasan cara pemeliharaan nya. Pemberian pakan selanjutnya oleh para peternak dengan cara membuat sendiri, pelaksanaan dilakukan pada tanggal 26 Juli 2019.

Hasil evaluasi dan pengontrolan pada tanggal 8 November 2019, ayam- ayam sudah berumur 3,5 bulan dengan bobot badan $1-1,3 \mathrm{~kg}$. Ayam dipelihara tanpa divaksin dan tanpa diberi obat-obatan, hanya pada air minum dicampur feed additive herbal berupa kunyit, ektrak kulit manggis dan ektrak buah mengkudu. Ayam yang dihasilkan bebas residu kimia dan termasuk ayam lokal semi organic. Ayam kampung/lokal ini sudah siap dipotong dan yang sebagian betina dan jantan terus dipelihara sebagai bibit untuk menghasilkan telur konsumsi dan telur tetas.

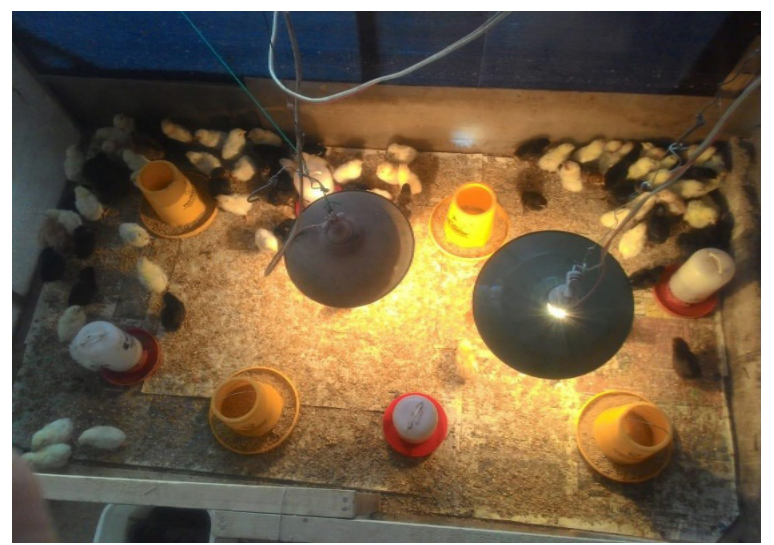

Gambar 3. Chick in Ayam Lokal

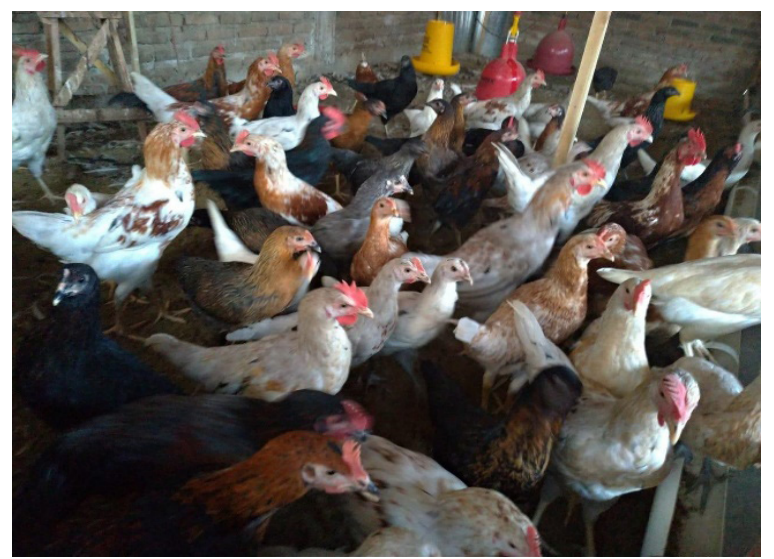

Gambar 4. Ayam Siap Panen

\section{SIMPULAN}

Pengetahuan anggota kelompok Tani Ranca bawang I dalam budidaya ayam kampung/Sentul secara umum dan pengolahan hasil produksi masih rendah, tetapi animo para peserta untuk menjadi peternak yang berhasil cukup besar.

Dari hasil evaluasi pre tes dan post test diperoleh hasil bahwa ada peningkatan pengetahuan mengenai budidaya pemeliharaan ayam kampung/lokal cukup berhasil. Pada pemeliharaan mulai DOC sampai siap dipanen untuk dipotong umur 3,5 bulan bobot badan dapat dicapai $1-1,3 \mathrm{~kg}$ dengan pemeliharaan tanpa di vaksin dan tanpa diberi obat-obatan sintesis, hanya diberi obat-obatan herbal.

\section{UCAPAN TERIMAKASIH}

PKM telah dilakukan dengan biaya dari Proyek Academic Leadership Grant (ALG), Direktorat Penelitian, Pengabdian kepada Masyarakat dan Inovasi Universitas Padjadjaran, Indonesia.

\section{DAFTAR PUSTAKA}

Alam, I.P. (2005). Resistensi ayam lokal jawa barat: ayam sentul. paper presented to lokakarya nasional inovasi teknologi pengembangan ayam lokal, Semarang, Indonesia.

Desa Cinanjung. (2019). (https://tanjungsarikec. sumedangkab.go.id)

Kementerian Pertanian Republik Indonesia. (2013). Keputusan Menteri Pertanian Nomor 698/ Kpts/PD.410/2/2013 Tentang Penetapan Rumpun Ayam Sentul.

Tuti Widjastuti, LovitaAdriani, W. Tanwiriah. (2016). Peningkatan Pendapatan Ibu-ibu PKK di Desa Tanjungsari dan Galura melalui Optimalisasi Usaha Beternak Ayam Kampung. Laporan Kegiatan PPMD Integratif, Direktorat Riset dan Pengabdian Kepada Masyarakat, Universitas Padjadjaran. Dharmakarya 